\title{
Ocorrência de aglutininas anti-Leptospira em ovinos do estado do Rio Grande do Norte, Brasil
}

\section{Occurrence of anti-Leptospira aglutinins in sheep of the Rio Grande do Norte State, Brazil}

\author{
Sérgio Santos de Azevedo, ${ }^{*}$ Clebert José Alves, ${ }^{* *}$ José Sóstenes Leite de Andrade, ${ }^{* *}$ Carolina de Sousa Américo Batista, ${ }^{\star \star}$ \\ Inácio José Clementino, ${ }^{* *}$ Fabiano Alexandre dos Santos**
}

\begin{abstract}
Resumo
Foram pesquisadas aglutininas anti-Leptospira em ovinos do estado do Rio Grande do Norte, Brasil. De agosto a outubro de 2001, foram examinados 115 soros de ovinos provenientes de 11 rebanhos situados em quatro municípios, pela prova de soroaglutinação microscópica, utilizando-se 12 sorovares de Leptospira spp. como antígenos. Foram considerados como títulos positivos os maiores ou iguais a 100. A caracterização dos sorovares mais prováveis levou em conta a titulação e a freqüência. Os resultados encontrados indicam uma soropositividade de 3,5\% (4/115). A distribuição dos sorovares mais prováveis foi: castellonis $(57,1 \%)$, autumnalis $(28,6 \%)$ e pomona $(14,3 \%)$.
\end{abstract}

Palavras-chave: leptospirose ovina; Leptospira; sorologia; ovinos.

\begin{abstract}
Anti-Leptospira agglutinins were investigated in sheep of the Rio Grande do Norte State, Brazil. From August to October of 2001, a total of 115 sheep sera from 11 flocks located in four municipalities were analyzed by the microscopic serum agglutination test using 12 Leptospira spp. serovars as antigens. It was considered as positive titers greater or equal to 100 . The most prevalent serovar were found crossing the results of frequency and titer of agglutinins. The results indicate that the seropositivity was $3.5 \%$ (4/115). The most prevalent serovar were: castellonis (57.1\%), autumnalis $(28.6 \%)$ and pomona $(14.3 \%)$.
\end{abstract}

Keywords: ovine leptospirosis; Leptospira; serology; sheep.

\section{Introdução}

A leptospirose é uma infecção de caráter zoonótico amplamente difundida no Brasil, que acarreta elevados prejuízos econômicos para a pecuária nacional. O seu principal impacto é o comprometimento do desempenho reprodutivo dos rebanhos acometidos (Vasconcellos, 1993). O controle da leptospirose envolve a aplicação de medidas que incluem a identificação das fontes de infecção, a eliminação do excesso de água do ambiente e a imunização sistemática dos susceptíveis com vacinas inativadas que contenham os sorovares de leptospiras presentes na região (Guimarães et al., 1982/1983; Faine et al., 1999).

Os inquéritos sorológicos realizados, a partir de 1980, em ovinos de diversas regiões do mundo retratam a variabilidade da distribuição de sorovares de Leptospira spp. nas diferentes localidades. Na Bolívia, poi e pomona (Ciceroni et al., 1997); no Chile, icterohaemorrhagiae, autumnalis e hardjo (Zamora et al., 1999); na Argentina, ballum, autumnalis e wolffi (Cacchione et al., 1980), pomona e butembo (Brihuega et al.,
1984) e wolffi, pomona e ballum (Draghi de Benitez et al., 1984); em Portugal, canicola, pomona, cynopteri, sejroe e icterohaemorrhagiae (Rocha, 1998); na Itália, hardjo (Ciucchinif et al., 1980) e castellonis, poi, sejroe, hardjobovis, copenhageni e cynopteri (Ciceroni et al., 2000); na Austrália, hardjo (Ellis et al., 1994); na Inglaterra e País de Gales, autumnalis, hardjo, bratislava e hebdomadis (Hathaway et al., 1982); na Holanda, hardjo (Pekelder et al., 1993); na França, grippotyphosa e sejroe (Trap e Garin-Bastuji, 1988); na Espanha, pomona e sejroe (Leon Vizcaino et al., 1987) e nos Estados Unidos da América, autumnalis, ballum, bataviae e bratislava (Ahl et al., 1992).

No Brasil, Santa Rosa e Castro (1963) encontraram 34\% de reatores em 400 ovinos do estado de São Paulo. Viegas et al. (1980) encontraram 22,8\% de reatores em 35 hemo-soros de ovinos do estado da Bahia, com destaque para os sorovares autumnalis e castellonis. Caldas et al. (1983), também na Bahia, verificaram $15,4 \%$ de positividade em 1.130 ovinos, com destaque para os sorovares autumnalis, castellonis e pomona. Ainda na Bahia, Caldas et al. (1993)

\footnotetext{
* Departamento de Medicina Veterinária Preventiva e Saúde Animal, Faculdade de Medicina Veterinária e Zootecnia, Universidade de São Paulo. Av. Prof. Dr. Orlando Marques de Paiva, 87, Cidade Universitária Armando de Salles Oliveira, 05508-000, São Paulo-SP. E-mail: sergio@vps.fmvz.usp.br.

** Departamento de Medicina Veterinária, Universidade Federal de Campina Grande, Campus de Patos, PB.
} 
encontraram 78,2\% (86/110) de positividade, com predomínio dos sorovares icterohaemorrhagiae, autumnalis e tarassovi. Langoni et al. (1995) examinaram 365 soros de ovinos de diferentes regiões do estado de São Paulo e encontraram $44,65 \%$ de positividade, com predomínio dos sorovares icterohaemorrhagiae, castellonis, hardjo, bratislava, andamana e wolffi.

Os diversos inquéritos sorológicos sobre a ocorrência de leptospirose ovina, já realizados no Brasil, oferecem informações valiosas. No entanto, como foram conduzidos em momentos diversos, em localidades específicas e empregadas coleções de antígenos distintas, as conclusões obtidas precisam ser atualizadas. Ressalta-se também a intensa mobilização nacional de animais e dos materiais de multiplicação animal que podem ter propiciado a introdução de variantes de leptospiras em áreas indenes.

No estado do Rio Grande do Norte, a ovinocultura encontrase em pleno desenvolvimento e vem assumindo papel de destaque na economia. Uma vez que a leptospirose é pouco estudada neste estado, conduzimos o presente trabalho, que teve como objetivo a realização de inquérito sorológico para investigar a ocorrência de ovinos reatores para a leptospirose, fixando-se o período de colheita das amostras entre agosto e outubro de 2001 e atentando-se para a determinação dos sorovares mais prováveis.

\section{Material e métodos}

Foram examinados 115 soros de ovinos de diversas raças, provenientes de 11 rebanhos situados em quatro municípios do estado do Rio Grande do Norte. Não foi aplicado nenhum critério de probabilidades para o estabelecimento do número de animais examinados. Os municípios contemplados foram escolhidos em função do conhecimento prévio de proprietários que concordaram com a realização da investigação. Os municípios trabalhados foram: Caicó, Ouro Branco, Jardim do Seridó e Parelhas. As colheitas de sangue foram realizadas no período de agosto a outubro de 2001.

Os soros foram examinados através da microtécnica de soroaglutinação microscópica (Galton et al., 1965), com uma coleção de antígenos vivos que incluiu os seguintes sorovares: icterohaemorrhagiae, tarassovi, wolffi, pomona, copenhageni, grippotyphosa, hardjo, autumnalis, castellonis, bratislava, hebdomadis e bataviae. Os soros foram triados na diluição de $1: 100$ e aqueles que apresentaram $50 \%$ ou mais de aglutinação foram titulados através do exame de uma série de diluições geométricas de razão dois. O título do soro foi a recíproca da maior diluição que apresentou resultado positivo. Os antígenos eram examinados ao microscópio de campo escuro, previamente aos testes, a fim de verificar a mobilidade e a presença de auto-aglutinação ou de contaminantes.

Para a determinação do sorovar mais provável, considerouse, para tanto, o sorovar que apresentou maior título e o maior número de animais caracterizados como positivos.

A caracterização da significância entre as diferenças observadas nas freqüências de animais reatores segundo o município de origem foi determinada através do teste de QuiQuadrado (Zar, 1999), pelo programa SPSS versão 11.0. O nível de significância adotado foi de 0,05.

\section{Resultados}

$\mathrm{Na}$ Tabela 1 encontram-se os resultados obtidos segundo o município de origem. Das 115 amostras de soro de ovino examinadas, quatro $(3,5 \%)$ foram reagentes frente a pelo menos um dos 12 sorovares da coleção de antígenos empregada. Não foi observada significância estatística entre a freqüência de animais reatores segundo a procedência $(P=$ $0,78)$.

Tabela 1: Freqüência de amostras de soro de ovinos reagentes pela técnica de soroaglutinação microscópica aplicada à leptospirose, segundo a procedência dos animais, no estado do Rio Grande do Norte, Brasil, no período de agosto a outubro de 2001

\begin{tabular}{|c|c|c|}
\hline \multirow{2}{*}{ Procedência } & \multicolumn{2}{|c|}{ SAM $^{1}$} \\
\hline & Animais Reagentes (\%) & Total (\%) \\
\hline Caicó & $2(4,4)$ & $45(39,1)$ \\
\hline Ouro Branco & $1(5,0)$ & $20(17,4)$ \\
\hline Jardim do Seridó & $1(3,6)$ & $28(24,4)$ \\
\hline Parelhas & $0(0,0)$ & $22(19,1)$ \\
\hline Total & $4(3,5)$ & $115(100)$ \\
\hline
\end{tabular}

1 - Soroaglutinação microscópica

$P=0,78$ (teste de qui-quadrado)

Na Tabela 2 é apresentado o número de amostras reagentes na soroaglutinação microscópica aplicada à leptospirose de acordo com os sorovares e seus respectivos títulos. O sorovar castellonis foi o mais freqüente, com quatro soros reagentes $(57,1 \%)$, seguido de autumnalis e pomona, com dois $(28,6 \%)$ e um $(14,3 \%)$ soros reagentes, respectivamente.

Tabela 2: Freqüência de amostras de soro de ovinos reagentes pela técnica de soroaglutinação microscópica aplicada à leptospirose, segundo o sorovar e os títulos sorológicos, no estado do Rio Grande do Norte, Brasil, no período de agosto a outubro de 2001

\begin{tabular}{lccccc}
\hline \multirow{2}{*}{ Sorovar } & \multicolumn{3}{c}{ Título } & \multirow{2}{*}{ Total } & \multirow{2}{*}{$(\%)$} \\
\cline { 2 - 4 } & $\mathbf{1 0 0}$ & $\mathbf{2 0 0}$ & $\mathbf{4 0 0}$ & & \\
\hline icterohaemorrhagiae & 0 & 0 & 0 & 0 & 0,0 \\
tarassovi & 0 & 0 & 0 & 0 & 0,0 \\
wolffi & 0 & 0 & 0 & 0 & 0,0 \\
pomona & 0 & 1 & 0 & 1 & 14,3 \\
copenhageni & 0 & 0 & 0 & 0 & 0,0 \\
grippotyphosa & 0 & 0 & 0 & 0 & 0,0 \\
hardjo & 0 & 0 & 0 & 0 & 0,0 \\
autumnalis & 1 & 1 & 0 & 2 & 28,6 \\
castellonis & 1 & 2 & 1 & 4 & 57,1 \\
bratislava & 0 & 0 & 0 & 0 & 0,0 \\
hebdomadis & 0 & 0 & 0 & 0 & 0,0 \\
bataviae & 0 & 0 & 0 & 0 & 0,0 \\
Total & $\mathbf{3}$ & $\mathbf{3}$ & $\mathbf{1}$ & $\mathbf{7}$ & $\mathbf{1 0 0}$ \\
\hline
\end{tabular}




\section{Discussão}

Os resultados obtidos revelam que no período de agosto a outubro de 2001 a leptospirose esteve presente no estado do Rio Grande do Norte em um nível de ocorrência relativamente baixo.

De fato, o cotejamento dos resultados do presente estudo com os obtidos em outras investigações conduzidas em diferentes países revela que o percentual de reatores encontrado $(3,5 \%)$ só foi superior aos obtidos por Hathaway et al. (1982), na Inglaterra e País de Gales (3,4\%), Leon Vizcaino et al. (1987) na Espanha (1,7\%), Pekelder et al. (1993) na Holanda, (3,3\%), e Rocha (1998) em Portugal (3,3\%), e inferior aos citados por Ciucchinif et al. (1980) na Itália (7,2\%), Cacchione et al. (1980) na Argentina (17,3\%), Brihuega et al. (1984) na Argentina (28\%), Draghi de Benitez et al. (1984) na Argentina (19,7\%), Trap e Garin-Bastuji (1988) na França (9,8\%), Ahl et al. (1992) nos Estados Unidos da América (32\%), Ellis et al. (1994) na Austrália (42\%), Ciceroni et al. (1997) na Bolívia (14,3\%), Zamora et al. (1999) no Chile (5,3\%), e Ciceroni et al. (2000) na Itália (6,1\%).

No Brasil, percentuais superiores foram observados por Santa Rosa e Castro (1973), no estado de São Paulo, Viegas et al. (1980) na Bahia, Caldas et al. (1983) na Bahia, Caldas et al. (1993) também na Bahia, e Langoni et al. (1995) no estado de São Paulo. A época escolhida para a realização do presente trabalho pode ter contribuído para o baixo valor de positividade obtido, pois as colheitas foram executadas justamente no período de seca, época em que são poucas as condições ambientais favoráveis para a disseminação da infecção (Faine et al., 1999), bem como outros fatores que influenciam na ocorrência de leptospirose, com destaque para a topografia, região, umidade e reservatórios silvestres e domésticos.

A predominância de animais reatores para o sorovar castellonis concorda com observações de outros autores e demonstra que esta amostra foi uma das mais freqüentes em ovinos (Viegas et al., 1980; Caldas et al., 1983; Caldas et al., 1993; Langoni et al., 1995; Ciceroni et al., 2000). A identificação deste sorovar em ovinos causa preocupação, que vai desde a contaminação do ambiente até a proteção específica, visto que não há imunidade cruzada, pois no mercado existem as vacinas compostas, basicamente, pelos sorovares canicola, grippotyphosa, hardjo, icterohaemorrhagiae e pomona.

\section{Referências}

AHL, A. S.; MILLER, D. A.; BARTLETT, P. C. Leptospira serology in small ruminants on St. Croix, U.S. Virgin Islands. Ann. N. Y. Acad. Sci., v. 16, p. 168-71, 1992.

BRIHUEGA, B. F.; PUEYO, J. M.; SORIA, E. H.; ROBLES, C. A.; CACCHIONE, R.A.; MARTINEZ, E. S. Leptospirosis in Nequen province, Argentina. Serological survey of animals and human beings. Vet. Argentina, v. 1, p. 462-466, 1984.

CACCHIONE, R. A.; CASCELLI, E. S.; SARAVI, M. A.; MARTINEZ, E. S. Difusión y importancia de las leptospirosis animal y humana en la Argentina. R. Med. Vet., v. 61, p. 236-247, 1980.

CALDAS, E. M.; SAMPAIO, M. B.; VIEGAS, E. A.; VIEGAS, S. A. R. A.; DIAS, E. M. M. Aglutininas antileptospira em ovinos e caprinos na região Nordeste do Estado da Bahia. Arq. Esc. Med. Vet. Univ. Fed. Bahia, v. 8, n. 1, p. 88-98, 1983.
Relativamente aos demais sorovares registrados, a análise comparativa com os achados internacionais revela que o sorovar autumnalis também foi encontrado na Argentina (Cacchione et al., 1980), na Inglaterra e no País de Gales (Hathaway et al., 1982), nos Estados Unidos da América (Ahl et al., 1992) e no Chile (Zamora et al., 1999). O sorovar pomona, na Argentina (Brihuega et al., 1984; Draghi de Benitez et al., 1984), na Espanha (Leon Vizcaino et al., 1987), na Bolívia (Ciceroni et al., 1997) e em Portugal (Rocha, 1998). No Brasil, o sorovar autumnalis foi encontrado no estado da Bahia (Viegas et al., 1980; Caldas et al., 1983; Caldas et al., 1993) e o sorovar pomona nos estados de São Paulo (Langoni et al., 1995) e da Bahia (Viegas et al., 1980; Caldas et al., 1983; Caldas et al., 1993).

No presente trabalho, os ovinos reatores não apresentavam quaisquer sinais clínicos da doença (infecção inaparente), o que é importante do ponto de vista epidemiológico, pois os animais assintomáticos eliminam constantemente o agente, garantindo a sua persistência no meio ambiente (Vasconcellos, 1993; Faine et al., 1999). Assim, esses animais podem funcionar como potentes fontes de infecção, já que nesta espécie a leptospirúria pode durar até 11 meses (Cousins et al., 1989), expondo o homem do meio rural ao perigo da doença ocupacional, uma vez que o contato se estabelece quase que diariamente com o animal. Dessa forma, a identificação de animais assintomáticos reatores para a leptospirose se reveste de importância na medida em que a identificação de sorovares prevalentes em uma determinada região poderá definir ações de controle da doença.

Em relação ao estado do Rio Grande do Norte (semi-árido nordestino), as preocupações devem ser acrescidas pelo fato de tais registros ocorrerem apesar das condições climáticas e luminosidade adversas para a sobrevivência das leptospiras fora do hospedeiro, pois segundo Torten (1979), embora exista a tendência de se relacionar altas precipitações com a ocorrência da doença, esta condição não é necessária para a manutenção do agente e sua transmissão, mesmo em zonas áridas, bastando para tanto a introdução do portador.

A distribuição geográfica dos animais reatores mostrou-se homogênea, uma vez que não ocorreu associação $(P=0,78)$ entre a freqüência de animais soropositivos situados nos diferentes municípios. Isto sugere que os mesmos fatores de risco da infecção estão presentes nos diferentes municípios investigados.

CALDAS, E. M.; VIEGAS, E. A.; VIEGAS, S. A. R. A.; REIS, R. S.; SANTOS, M. S. Aglutininas antileptospira em hemo-soros de animais domésticos no Estado da Bahia, 1990-1993. Arq. Esc. Med. Vet. Univ. Fed. Bahia, v. 16, n. 1, p. 49-59, 1993.

CICERONI, L.;BARTOLONI, A.; PINTO, A.; GUGLIELMETTI, P.; VALDEZ VASQUEZ, C.; GAMBOA BARAHONA, H.; ROSELLI, M.; GIANNICO, F.; PARADISI, F. Serological survey of leptospiral infections in sheep, goats and dogs in Cordillera province, Bolívia. New Microbiol., v. 20, n. 1, p. 77-81, 1997.

CICERONI, L.; LOMBARDO, D.; PINTO, A.; CIARROCCHI, S.; SIMEONI, J. Prevalence and antibodies to Leptospira serovars in sheep and goats in Alto Adige-South Tyrol. J. Vet. Med. B. Infect. Dis. Vet. Public Health, v. 47, n. 3, p. 217-223, 2000.

CIUCCHINIF, F.; PICCININNO, G.; LILLINI, E.;PISTOIA, C. Serological survey of sheep for leptospirosis in the Rome province of Italy. Arch. Vet. Ital., v. 31 , p. $37-44,1980$. 
COUSINS, D. V.; ELLIS, T. M.; PARKINSON, J.; McGLASHAN, C. H. Evidence for sheep as a maintenance host for Leptospira interrogans serovar hardjo. Vet. Rec., v. 124, p. 123-124, 1989.

DRAGHI DE BENITEZ, M. G.; ZURBRIGGEN, M. A.; VANZINI, V. R.; ROCHINOTTI, D.; HOMSE, A. C. Serological survey for ovine leptospirosis in Corrientes province, Argentina. Vet. Argentina, v. 1, p. 336-340, 1984.

ELLIS, G. R.; PARTINGTON, D. L.; HINDMARSH, M.; BARTON, M. D. Seroprevalence to Leptospira interrogans serovar hardjo in merino stud rams in South Australia. Aust. Vet. J., v. 71, n. 7, p. 203-206, 1994.

FAINE, S.; ADLER, B.; BOLIN, C.; PEROLAT, P. (Ed). Leptospira and Leptospirosis. 3. ed. Melbourne: MediSei, 1999. 272 p.

GALTON, M. M.; SULZER, C. R.; SANTA ROSA, C. A.; FIELDS, M. J. Application of a Microtechnique to the agglutination test for leptospiral antibodies. Appl. Microbiol., v. 13, n. 1, p. 81-85, 1965.

GUIMARÃES, M. C.; CÔRTES, J. A.; VASCONCELLOS, S. A.; ITO, F. H. Epidemiologia e controle da leptospirose bovina. Importância do portador renal e do seu controle terapêutico. Comum. Cient. Fac. Med. Vet. Zootec. Univ. São Paulo, v. 6/7, n. 1/4, p. 21-34, 1982/1983.

HATHAWAY, S. C.; LITTLE, T. W. A.; STEVENS, A. E. Serological survey of leptospiral antibodies in sheep from England and Wales. Vet. Rec., v. 110, p. 99-101, 1982.

LANGONI, H.; MARINHO, M.; BALDINI, S.; SILVA, A. V.; CABRAL, K. G.; SILVA, E.D. Pesquisa de aglutininas antileptospíricas em soros de ovinos no estado de São Paulo, Brasil, utilizando provas de macroaglutinação em placa e soroaglutinação microscópica. $R$. Bras. Med. Vet., v. 17, n. 6, p. 264-268, 1995.
LEON VIZCAINO, L.; HERMOSO de MENDONZA, M.; GARRIDO, F. Incidence of abortions caused by leptospirosis in sheep and goats in Spain. Comp. Immunol., Microbiol. Infect. Dis., v. 10, p. 149-153, 1987.

PEKELDER, J. J.; WESTENBRINK, F.; VELLEMA, P.; PETERSE, D. J.; BOKHOUT, B.A.; FRANKEN, P. Serological study of the occurrence of $L$. hardjo in sheep in the Netherlands. Tijdschr Diergeneeskd, v. 118, n. 13, p. 433-435, 1993.

ROCHA, T. A review of leptospirosis in farm animals in Portugal. Rev. Sci. Tech., v. 17, n. 3, p. 699-712, 1998.

SANTA ROSA, C. A.; CASTRO, A. F. P. Presença de aglutininas antileptospira em soros de ovinos e caprinos do Estado de São Paulo. Arq. Inst. Biol., v. 30, p. 93-98, 1973.

TORTEN, M. Leptospirosis. IN: STEELE, J. H.; STOENNER, H.; KAPLAN, W. (Ed.). Handbook series in zoonosis. Seccion A: Bacterial, rickettsial and micotic diseases. CRC Press: Boca Raton, 1979. p. 363-421.

TRAP, D.; GARIN-BASTUJI, B. Leptospirosis in sheep. B. Mens. Soc. Vet. Prat. Fr., v. 72, p. 283-292, 1988.

VASCONCELLOS, S. A. Leptospirose Animal. ENCONTRO NACIONAL EM LEPTOSPIROSE, 3., Rio de Janeiro, Anais...1993, p. 62-66.

VIEGAS, E. A.; VIEGAS, S. A. R. A.; CALDAS, E. M. Aglutininas antileptospiras em hemossoros de caprinos e ovinos no Estado da Bahia. Arq. Esc. Med. Vet. Univ. Fed. Bahia, v. 5, n. 1, p. 20-34, 1980.

ZAMORA, J.; RIEDEMANN, S.; TADICH, N. A serological survey of leptospirosis in sheep in Chile. Rev. Latinoam. Microbiol., v. 41, n. 2, p. 73-76, 1999.

ZAR, J.H. Bistatistical analysis. 4. ed. Upper Saddle River: Prentice Hall, 1999. 663 p. 